\title{
Student Perspectives on Language Learning in a Study Abroad Context
}

\author{
Valerie A. Pellegrino
}

The Obio State University

\section{Introduction}

In the classroom, of course, the instructor to a large extent calls the tune. But outside the classroom, during study abroad in particular, it is the learner's views that matter, for they shape the learning opportunities that arise and the learning strategies that will be employed. (Miller and Ginsberg, 1995, 243)

Students, teachers and researchers alike commonly agree that one of the most effective and efficient means for becoming proficient in a second language is study abroad. Learners who opt to spend a significant amount of time in the country of the target language (TL) are exposed to frequent and intense opportunities to interact with native speakers, to activate their linguistic and sociolinguistic skills to achieve real communicative goals, and to experience the tangible and visible manifestations of the target culture (TC) first hand. Numerous statistical studies attest to the value of study abroad (SA) in terms of proficiency outcomes (e.g., Stansfield 1975, Carroll 1967, Freed 1995), essentially establishing study abroad as the sine qua non of successful language acquisition. Yet, as with most second language acquisition (SLA) research, the majority of studies investigating study abroad have been highly product-oriented, focusing on the measurable advances students make in language proficiency and linguistic knowledge while abroad. Relatively little research considers the process of study abroad, i.e., the actual experiences and perspectives of learners living in a foreign country, removed from their home culture and immersed in the target language. This chapter offers an overview of 
research that has been performed over the past 35 years concerning study abroad participants' perceptions of language and language learning, the role of the language classroom, the influence of the social environment, and the study abroad experience as a whole. The impact of students' perceptions on the language learning process and the value of student perspective research in the field of SLA are also considered.

\section{Methodological Is sues}

A large part of research regarding learners' perspectives in SA has been conducted using "introspective" methods of data collection (such as diaries, interviews, and other means of self-report) and qualitative forms of analysis (case studies, ethnographies, and others). Research methods such as these have long been the focus of considerable debate among scholars (see, for example, Nunan 1991, Larsen-Freeman and Long 1991). Case studies, personal diaries, and introspective interviews are often characterized as unscientific due to their idiosyncratic nature and lack of objectivity (Eisner and Peshkin 1990). Moreover, introspective techniques ask that learners report on processes and events within their learning of which they may not even be aware or that they may be unable to characterize adequately. Since these techniques by design generally do not employ large cohort groups, random selection of subjects, or control groups, the validity and reliability of the studies are difficult or impossible to establish, and the results are of questionable generalizability.

Despite the apparent scientific limitations of qualitative methods, however, researchers in SLA have increasingly recognized the unique insights introspective techniques can provide concerning students' language use and the language learning experience. Kathleen Bailey's extensive review (1983) of diary studies, in which she examined the roles of competitiveness and anxiety in adult language learning, serves as a fine example of how learners' self-reports have allowed researchers to peer into the private thoughts, expectations, and attitudes of learners in ways that observations and quantifiable scales could not (Gillette 1987, Cohen 1987). Using qualitative methods, the researcher can gain more than a surface understanding of a phenomenon, delving deep into the personal experiences of individuals and painting a much more intense picture than that allowed by statistical methods. In fact, one of the greatest benefits of 
introspective research is something that has been seen by many to be an inherent flaw in the methodology; that is, the data collected through these methods consist of the biased, subjective perceptions of the study's participants (Schmidt and Frota 1986). Proponents of "hard science" research methods often consider data filtered through personal opinion to be tainted and unscientific without objective and verifiable controls. Yet Bailey and Ochsner (1983) point out that "it does not matter if someone actually received a bad grade on a test; what interests us is how the author perceives that bad grade - as an embarrassment or as an irrelevance not even worth mentioning in the report" (192). Whether the learners' descriptions of the events happening around them or in their language learning are accurate is not the salient point, but rather how learners perceive those events:

The students obviously believe that something significant has happened to them, even though they may have difficulty articulating just what that is. In spite of such difficulties, their perceptions of the experience will belp educators gain valuable insights into what happens to students while enrolled in an education abroad program. (Laubscher 1984, xi)

Students' perceptions of the language, their own learning, and the study abroad experience hold great value for understanding the language use and social behaviors of students immersed in an L2 environment. Studies in social psychology have indicated that individuals will behave according to the perceptions they have of themselves, other people, their environment, and the attitudes they perceive others to have toward them (Aronson 1995). Investigations into the phenomena of self-fulfilling prophesies, stereotypes, social conformity, and beliefs have demonstrated that "the belief can come to create the world in which we live ... a subtle context had influenced beliefs and expectations that in turn affected behavior and subsequently affected the next round of perceptions" (Aronson 157-158). Thus, viewing the perceptions learners have about themselves and about the study abroad enterprise, whether objectively factual or not, can enlighten researchers, pedagogues, and program administrators, as well as the students themselves, about the learning and language use behaviors and ultimate success of students during in-country study. 
Since students' perceptions are formed according to their individual social and linguistic experiences, the study of student perceptions is individualistic, and, thus, difficult to generalize to larger populations. Moreover, although diaries and interviews provide deep insights into an individual's personal experience, they cannot be thought to represent the experiences of all SA participants. As ethnographers explain, the goal of introspective research is not to gain breadth of applicability but rather depth of understanding, that is, not to generalize findings to a larger population at all, but rather to deepen the researcher's understanding of the individual's SA experience. Nevertheless, several SLA researchers have attempted to minimize the problem of generalizability by surveying larger numbers of SA participants and by compiling the perceptions of SA participants from across a wide variety of language study experiences. As this chapter will demonstrate, there is a considerable amount of accord among the findings of studies conducted across techniques and study abroad contexts. The following sections will review articles conducted using a wide array of methodologies: analyses of individual language learning journals, written by the researchers themselves; analyses of thirdparty diaries and interviews written by members of single or multiple study abroad groups; questionnaire-driven case studies of single or multiple study abroad groups; and case-studies that include a mixture of qualitative and quantitative techniques. These studies investigate the experiences both of learners studying independently and of those enrolled in formal SA and language immersion programs, some attending language classes, others not. In these studies, some SA participants traveled abroad with no prior knowledge of the target language and with language acquisition as a secondary goal, while others had extensive prior training in the target language and were traveling specifically to improve their proficiency. Moreover, the studies have been conducted across a broad spectrum of cultural and linguistic settings, including Spain, Brazil, Denmark, Russia, Japan, China, France, Tunisia, Iran, Guatemala, Germany, England, Taiwan, Israel, Egypt, Australia, Mexico, Italy, and Kenya. Thus, by comparing and contrasting the findings of various studies of the perspectives of adult SA participants in disparate learning environments, it is possible to identify common findings concerning the SA experience and increase the ultimate utility of those findings.

The following sections will summarize the findings of student per- 
spective studies in terms of students' perceptions of the target language and how it is to be learned, the language learning classroom, the social environment, and the SA experience as a whole. Within each of these areas, the effect of students' perceptions on their L2 acquisition is considered.

\section{Learners'Perceptions of Language and Language Learning}

As the quote by Miller and Ginsberg (1995), offered at the opening of this chapter, states, learners develop their own ideas about what makes a language and how languages are learned, and these ideas lead learners to make choices in their language use and learning behavior that may affect their ultimate success in language acquisition. This section will summarize the findings of studies that have examined these perspectives and the impact of such perspectives on L2 acquisition.

The research team that has devoted the most direct attention to learners' perceptions of language and language learning is that of Miller and Ginsberg (1995). In their study of American students studying Russian on formal programs (two semester-length and one summer-length programs) in Moscow and St. Petersburg, ${ }^{1}$ Miller and Ginsberg examined students' "folklinguistic theories," i.e., their perspectives on the nature of language, how it is housed in the human mind, and how it is learned. Miller and Ginsberg analyzed students' introspective diaries in which participants were asked to describe episodes where they used the language or learned something new. Based on these descriptions, Miller and Ginsberg reached three conclusions. First, students' ideas about the elements of a language appear to be classroom driven and neglect many of the features of language for which study abroad is the most advantageous. For example, students perceive language as a fixed system in which words and syntax are the primary elements, with a unified system of set rules and meaning that is carried by the words alone. Moreover, students believe there is only one correct way to say things in Russian, and success in Russian means producing grammatically correct utterances. Such beliefs limit the second language to its textbook form, ignoring the pragmatic uses and communicative flexibility that is so characteristic of authentic speech. Second, students expressed beliefs that their speaking improves or deteriorates in various situations (such as drinking alcohol or interacting with 
strangers), which subsequently leads them to choose language use opportunities based on these beliefs. Students often expect that language learning can occur only under certain circumstances; for example, many students appraise auditory input as having little or no value for language learning, and thus reject opportunities in which passive participation may provide abundant practice in listening and comprehension. Third, students characterize language learning as an incremental, step-by-step process, similar to a syllabus-driven classroom curriculum, rather than a natural cyclical process with developmental advances and temporary setbacks. Miller and Ginsberg contend that based upon these views of language and the language learning process, views that appear to emanate from the classroom experience, learners choose opportunities to practice speaking based on what they believe to be most effective and accurate. Consequently, they often fail to realize and take full advantage of the unique opportunities offered by the in-country environment for developing communicative competence in the $\mathrm{L} 2$.

Another perception of the language learning process that can potentially limit SA participants' success in L2 acquisition is the "language myth," reported by Wilkinson (1997). In her ethnographic examination of two young anglophone women studying French during a summer abroad in France, Wilkinson highlights what she calls the "language myth," a common but erroneously-held belief that contends that study abroad will ultimately and inevitably lead to language acquisition due to the sheer number of hours students spend simply exposed to the language. Wilkinson's participants, however, reported that contrary to the expectations of the "language myth," English, not French, was often the primary mode of communication outside of the classroom since students tended to cluster together and experienced difficulties meeting native speakers (NSs) with whom to speak French. Schumann (1980), Blender (1998), and Pellegrino (1997a) report similar trends in which SA participants chose to speak their native language over the target language.

There are numerous social, cultural, and psychological factors that may cause learners to avoid using the target language and reject opportunities to speak, as will be discussed in subsequent sections of this chapter. However, such avoidance behavior often is seen by researchers as indicative of students with poor motivation and a lack of discipline. For example, DeKeyser (1991) writes that "the sheer number of hours spent in the 
native-speaking environment provides a huge amount of comprehensible input for all students, and a sizable amount of speaking practice for those who are willing to make an effort"2 (116); and Wilkinson notes Cholakian's (1992) view that only the "well-motivated and resourceful student ... understands the value of conversing with natives and avoiding compatriots" (22, quoted Wilkinson 8). Wilkinson (1997) characterizes this attitude as the "lazy student" myth. She points out that there are multiple other reasons beyond that of learners' motivation and effort that contribute to learners' ultimate language use and proficiency. Dismissing learners who experience social, cultural, and conceptual difficulties with a wave of the hand and the accusation of laziness would prevent improvement and discourage further effort, thus creating a self-fulfilling prophecy of failure.

These studies of students' perceptions have suggested that when studying abroad, students retain a view of the language as an academic, classroom-based topic to be mastered, leading them to choose practice opportunities concordant with that view. Moreover, they tend to evaluate their own performance in the L2 according to this classroom-based view, meaning that successful L2 use is measured by correct grammatical form and target expressions, rather than achievement of the communicative goal. Thus, if learners fear failure and perceive grammatical mistakes as negative and experimental phraseology as leading to potentially incorrect L2 usage, they may reject opportunities to experiment if they believe they are unable to do so accurately. In these ways, learners' perceptions condition their L2 use and choice of learning opportunities.

Student perspective studies don't only speak of learners' academic view of the target language, but also shed light on the the ways in which learners increase their L2 use and improve their linguistic knowledge and communicative capabilities. Lennon's (1989) study identified some of the ways in which learners described the language acquisition process and factors that affected that process. As advanced learners of English, his participants could pick out meaning from context much more easily than beginning language learners, and they consciously tried to use expressions they encountered in L2 input. Moreover, as learners advanced, their fear of making mistakes abated, allowing them to communicate more freely in the L2. Consequently, learners also reported that they perceived themselves as improving in "fluency" more than "grammar." Robinson (1995) 
also reported in her study of American students in Russia that students perceive themselves as focusing more on communication than on accuracy when interacting with NSs. Lennon notes additional language learning strategies undertaken by students, including listening initially (rather than actively participating), consciously using expressions they heard or read, seeking out feedback, or experimenting with a more sophisticated register.

While Miller and Ginsberg (1995) reported that students were very concerned with forming grammatically correct utterances, Lennon (1989) and Robinson (1995) found that their participants perceived themselves as more focused on communication than on accuracy. There may be many reasons for this discrepancy. First, the discrepancy between these findings reflects the difference between the beliefs learners espouse and the behaviors they report (note that Miller and Ginsberg worked with the same group of participants as Robinson did). Learners do not always behave in the manner in which they perceive themselves. Second, the discrepancy may be a result of longer periods of immersion and more advanced language ability, as Lennon noted that more advanced students were better able to pick meaning from context and thus, able to focus on communicative context with greater facility than those at a more elementary stage. Third, the discrepancy may arise due to individual learner differences among the studies' participants, as each study focuses on the individual. Finally, the discrepancy may be due to the difference between students' goals and expectations. As the upcoming sections will demonstrate, students look forward to participating in SA programs in order to interact with native speakers and develop their oral proficiency, thus intending to focus on communication in the L2. However, the frame of linguistic knowledge students receive in the domestic foreign language classroom may persist in learners' characterization of how they perceive language and language learning in the SA environment. The following section addresses the influence of the classroom in SA more fully.

\section{The Role of the Classroom}

Certainly, as the student perceptions highlighted in the previous section suggest, one of the greatest benefits of in-country study is the abundance of opportunities for spontaneous, i.e., non-classroom, language 
use through interaction with native speakers in culturally authentic settings. This, of course, raises questions as to the value of formal language classes in study abroad programs. Does structured, teacher-managed language instruction sufficiently contribute to the development of learners' linguistic knowledge and communicative proficiency to warrant the costs incurred for pedagogic materials and salaries? And is the time learners sacrifice behind the desk worth the loss of time spent in informal interactions? Researchers have reported that SA participants often derogate the language classroom during their time in-country and see classwork as less productive than socializing with native speakers. For example, Pellegrino (1996a, 1996b) found in her survey of American students preparing to leave for Russia that $87 \%$ agreed ( $54 \%$ strongly) that they believed they would learn more Russian through speaking with native speakers than in a classroom setting. Upon their return to the U.S., an even greater majority of the same group confirmed that class time had less value than socializing, as 91\% agreed (59\% strongly) that they believed that learning Russian from their Russian friends was better than in the group with Americans. Although it is not clear how students interpreted the word "better," many explained their opinions more fully in an open-ended survey item. For example:

I learned more from my charming, autbentic Russian bost family than I could and have ever learned in class.

I found that I learned very little in in-class situations, because in class I was more likely to stick with constructions and words I already knew. Outside of class I was much more willing to take chances when speaking.

I don't learn most of it (the language) in class.

I learn better when speaking with Russians about various topics rather than in a classroom setting.

I find I learn new words and vocab more by doing stuff than just in class (Pellegrino 1996a).

Lennon (1989) also reports that his participants suggested that "psy- 
chologically, speaking English [the L2] in the classroom lacks communicative purpose which renders it less effective [than informal interaction] as practice" (384). Other researchers (Schmidt and Frota, 1986; Robinson, 1995; Brecht and Robinson, 1995) report similar findings.

While certainly not all students derogate the SA classroom, the students' opinions reported above are difficult to deny. Students' devaluing of formal instruction can influence their behaviors while living in country, leading them to drop classes (Schmidt and Frota, 1986) and reject the opportunities offered them in class due to negative attitudes (Brecht and Robinson, 1995) and "tuning out" (Pellegrino, 1997a). Taking a deeper look into introspective data, however, researchers have found that the positive impact of formal instruction can be considerable for students immersed in target language culture.

In a study specifically addressing the issue of formal instruction during study abroad, Brecht and Robinson (1995) analyzed diaries, interviews, and observations of American college students studying for one semester in Moscow and St. Petersburg, Russia, from Fall, 1989, to Summer, 1991. They reported that of the students interviewed, the opinions gathered were highly mixed: "Four said that the classes were useful and five considered the amount of class time 'not too much.' But five thought the classes were a 'waste of time' or 'not up to my expectations' " (320). As in other studies noted here, Brecht and Robinson report that the students often derogated the classroom. However, Brecht and Robinson note that when giving substantive criticisms of the classroom's value for linguistic development, students generally offered explanations that would attribute their negative reactions to things not inherent in the classroom environment. For example, students often suggested how the classes could be improved, thus indicating that students do not generally find classes to be valueless, but, perhaps, ineffective as they are. Students also reported feeling confused and frustrated by discrepancies between information gained in the class and that provided by native speakers outside the class. Brecht and Robinson explain that students were "accustomed to learning to trust one authority on what 'correct' Russian was" and had difficulty accepting the rich variation of pragmatic usage available in the native speech community (328). Furthermore, differences between the cultures of the Russian classroom and the American classroom often led to misunderstandings and negative attitudes among stu- 
dents and teachers. Once again, cultural differences, while valid, do not speak to the inherent value of formal instruction for language learning incountry.

In their analysis of learners' journals and interviews, Brecht and Robinson looked not only at explicit comments learners made about the classroom environment, but also looked at L2 use events learners reported taking place outside of the classroom. Close analysis of these events indicated that despite learners' derogation of formal instruction, classwork positively influenced out-of-class L2 use in four principle ways. First, classes helped learners focus their out-of-class language practice by setting goals for language use and providing a neatly packaged vocabulary and grammar by which to achieve those goals. Second, class interactions helped learners activate information and language skills previously known only passively. Third, learners reported that formal instruction augmented their comprehension by helping them access nuances of vocabulary and form that learners might otherwise miss in natural input. Finally, the language class offered a forum in which learners could understand communicative breakdowns they had experienced and troubleshoot future problems. Thus, Brecht and Robinson discerned that despite students' derogation of the classroom, the events they reported showed that students benefited greatly from the SA classroom component; when students are critical of the classroom, it is primarily due to factors other than the pedagogically beneficial elements of instruction.

Among the findings reported by Brecht and Robinson, many are supported and replicated in other studies. Schmidt and Frota (1986), for example, present an analysis of Schmidt's five-month journal of independent study of Portuguese in Brazil. During his first three weeks in Brazil, Schmidt lived with no knowledge of Portuguese and no formal instruction. He reports being unable to sustain communicative contact with native speakers during this period. However, the information he received on his first day of class immediately increased his comprehension and gave him the information he needed to meet basic communicative goals. Like Brecht and Robinson, Schmidt and Frota report that the classroom provided quick answers to communicative problems encountered out of the classroom. Likewise, they report that the classroom context helped focus language learning outside of the classroom by directing Schmidt's conscious attention to particular features of the unstructured input: "[he] 
noticed some verbs in input before they were taught ... but more commonly he noticed verb forms in input immediately after they were taught" (279). Schmidt and Frota conclude that formal instruction is important during study abroad, although not essential. Interestingly, they also found that interaction with native speakers, while providing the necessary input for language learning, was also not sufficient in and of itself for language learning in that it doesn't guarantee grammaticality or idiomaticity.

Robinson (1995) also reached many of the same conclusions as those of Brecht and Robinson (1995) and Schmidt and Frota (1986). In an analysis of her own and others' language learning diaries on a Russian study abroad program, she listed five ways in which the SA classroom is linked to students' use of language outside of the classroom. Like Schmidt and Frota, she notes that the classroom environment is often replicated in informal interactions: first, in terms of the type of language students use, and second, in terms of the topics of conversation. Third, she notes that formal instruction aids students' conscious application of classroom material out of class, helping them intentionally plan intonational patterns, vocabulary, and grammatical structures to receive desired pragmatic effects. Fourth, the classroom offers students a framework by which to assess their own progress and helps them focus on improving their language skills. Finally, the assigned homework helps learners continue to concentrate on linguistic issues and offers learners a structured opportunity for "multiple exposure" to vocabulary and grammatical forms. Like Schmidt and Frota (1986), Robinson characterizes the classroom as a forum for verifying linguistic information and resolving communicative difficulties encountered outside of class.

While the classroom offers learners a somewhat open forum in which to clarify the linguistic input they receive in the informal environment, Laubscher (1994) suggests that the classroom environment itself is not the critical element, but rather the "decisive intervention in the interpretive process" (107) that may be offered by native speaker (NS) informants. Laubscher conducted a qualitative study of the experiences of thirty university students studying abroad in the fall of 1990 in twelve locations throughout Europe, the Middle East, the Far East, and Australia. His study addressed the ways in which learners independently use their out-of-class experiences to enhance the cross-cultural learning process. Laubscher found that learners cited three primary means by which they 
gathered informational input in the informal environment: participant observation, personal interaction, and travel. However, Laubscher also notes that although these techniques provide the input essential for experiential learning, in that they raise learners' awareness of the information, understanding of the information does not naturally follow. By continuing to interpret the new input on the basis of past personal experience, the participants move no closer to developing comprehension of the world around them. Explanation from native informants is important for reframing learners' experience from a target culture perspective which helps move them closer to abstract conceptualization. Thus, Laubscher stresses the importance of caretaker intervention to help learners make the most of their non-class time.

As these studies suggest, formal instruction plays an important role in learners' development of L2 knowledge and proficiency during study abroad. However, some studies report that the classroom may actually hinder language development by perpetuating folklinguistic theories. Miller and Ginsberg (1995) noted that students' folklinguistic theories of language learning led them to attempt to recreate classroom situations in informal interactions with NSs. They present diary entries that suggest that learners at times become offended and frustrated when their NS interlocutors do not aid their communication or sustain interactions the way teachers would in a pedagogical setting. Similarly, Wilkinson's (1998) ethnographic study of seven American undergraduate women studying on a summer program in France also suggests that the classroom environment can have a somewhat negative, structural influence on students' language learning. Wilkinson offers transcripts of NS-NNS (nonnative speaker) interactions and follow-up interviews that show how learners look for vestiges of classroom norms in interactions with NS interlocutors. Learners maintain their expectations of classroom discourse norms (e.g., quick topic changes) and caretaker roles (e.g., NS direction of conversation) in informal interactions, which can lead to negative attitudes and inappropriate behaviors both on the part of the learners and the NS interlocutors. Although these two studies suggest that classroom learning may have a restricting effect on students' vision of learning in an informal environment, the overall benefit to learners may far surpass the cost. The paradigm of classroom learning is instilled in students from a very early age, and the vast majority of language learners begin their study 
in a formal setting. Thus, even without a classroom component, students studying language in-country will likely continue to think of language learning with somewhat of a textbook mentality. With a classroom component, the language learning process may be expedited as students receive scaffolding upon which to place L2 input and intervention from a knowledgeable NS who can help reshape their frame of reference to that of an NS.

As Schmidt and Frota (1986) found, the classroom is not necessary for learning, yet the informal environment and the classroom appear to balance each other out, as the informal environment provides the input necessary for learning, but does not guarantee the grammaticality and idiomaticity offered in the classroom. Although students may perceive the classroom as a negative aspect of their SA program in comparison with formal interaction, its role as a learning management center, informational resource center, and source of "decisive intervention," indicate that its value may be worth the costs. The most important outcome of introspective research on the role of the classroom, however, is the recognition of students' negative perceptions of formal instruction during SA, since students tend to act on those perceptions, regardless of the classroom's objective benefits.

\section{Study Abroad and the Social Environment}

Although valuable, the classroom is not what attracts most learners to study abroad. Rather, it's the potential for extensive social interaction in the target language. Many researchers have focused considerable attention on learners' perceptions of their social environment and the importance of communicative interaction for their L2 development. According to studies such as that of Laubscher (1994) and Schmidt and Frota (1986), mentioned earlier, learners require large amounts of authentic linguistic input in order to advance their understanding of the language, and this may best be achieved through meaningful interaction with native speakers. Campbell (1996), for example, attributed her successful acquisition of German during study abroad to her close and frequent interaction with a group of NS friends. Consequently, she attempted to replicate this intimate social network in her relations with her teachers in Mexico in order to maximize her acquisition of Spanish while in Cuernavaca, Mexico. 
According to her analysis of her own language learning journal, Campbell reports:

From my review of the sheer numbers of relevant journal entries, socializing with the teachers emerges clearly as the most important influence on my language learning in Mexico, more important than my classroom study, associations with the family I lived with, or anything else. (206)

Through her interaction with the Mexican teachers and her Mexican boyfriend, Campbell reports improvements in automaticity of speech and her sense of social salience as a member of the Mexican group.

Campbell made an active, strategic decision to immerse herself in the target language community knowing from previous experience the linguistic benefits to be obtained through informal interactions. Other researchers have also noted the importance of socializing in the L2. Based on an open-ended survey of 23 adult learners of Spanish coming from twelve different countries, Keating (1994) notes that one of the most important factors in students' acquisition of Spanish was the social setting. "This interaction with competent speakers," Keating notes, "provides the opportunity to discover one's language gaps, and the negative feedback inherent in social responses to one's failures to communicate increase motivation to be more attentive to native speakers" (61). These findings, in addition to the sentiments of students comparing the usefulness of class time to social time, presented in the last section, indicate that social interaction in the L2 plays an extremely significant role in the language learning of SA participants.

Despite the importance of personal contact with NSs, however, many students report that, unlike Campbell, they are unable to achieve the social interaction goals they set for themselves. Pellegrino (1996a; 1996b) reports that two thirds of the 76 students polled in her study responded that, realistically speaking, they hadn't put as much effort into speaking with Russians outside of the class as they might have, despite their pre-program intentions. Kline (1993) also reports that she and the participants of her ethnographic study of the development of literacy in the French SA social environment expected, as one participant wrote, "to immerse myself into the French culture and learn from first-hand experiences rather than only through books" (263-264). However, the ethno- 
graphic data upon which Kline's study is based reveal that students often rejected opportunities for social interaction when they arose. There may be several reasons for such behavior.

One explanation may lie in the difficulties inherent in cultural adaptation. Bacon (1995) describes the use of dialogue journals between SA participants (teachers of Spanish) and their instructors as a pedagogical technique for understanding and discussing cultural phenomena. As an added benefit, the dialogue journals provided meaningful insight into the participants' adaptation to Spanish culture. Bacon reports that the participants' journal entries indicated that participants follow a pattern of cultural adjustment similar to that proposed by Hanvey (1979): tourism, deviance, intellectualization, and assimilation. In the "tourism" stage, the learners are fascinated by the new culture, and differences seem "quaint." In the second stage, however, the differences appear grotesque and deviant, until learners reach the third stage, in which they begin to intellectualize and seek explanations for what they see (similar to Laubscher's [1994] assertion that learners need "decisive intervention" in order to form an abstract conceptualization of new input). Only then can learners assimilate into the new culture in the fourth and final stage. Bacon explains that "all the journals reflected some evidence, though not concurrently, of Hanvey's second stage of cultural adjustment" (203), manifested as "a sense of loss of control over one's immediate environment" (200). Participants' responses to this feeling included breakdowns in relationships with Spaniards, difficulty communicating in Spanish, negative attitudes toward NSs, and feelings of isolation, thus leading to reduced L2 use and stunted understanding of the target culture. Similarly, Wilkinson (1997) describes what she terms the "culture myth," explaining that learners who study abroad often expect that their time in another country will lead to an understanding and appreciation of the new culture. Based on her ethnographic data, Wilkinson reports that students often experience frustrating and confusing misunderstandings, noting, "clearly, exposure $^{3}$ to cultural differences during an overseas stay does not necessarily translate into the cross-cultural understanding promised" (5). Negative perceptions of the target culture, typical in the cultural adjustment process, can lead learners to experience difficulty in or avoid interactions with NSs.

Other cultural limitations may depend on the nationality of the 
learner in relation to the target culture and other members of the learner's own culture. As noted before, Schumann (1980) reports in her own language learning diary that as an American in Iran, her connections to the expatriate community had a negative impact on her attitudes toward studying Farsi. She also notes that as an English speaker, she had difficulty finding opportunities to interact in Farsi, since NSs, upon hearing her accent, immediately broke into English. In an ethnographic study of the perceptions of resident directors of American groups in Russia, Blender (1998) presents examples of a similar phenomenon to that of Schumann's expatriate connection, in which students tend to group together with other Americans and speak English, thus cutting off opportunities to interact in Russian with each other or with NSs. Blender refers to social psychological theories of group dynamics, noting that the construction of group isolating barriers is a typical group behavior that requires awareness and intervention to overcome. Although these studies look at the negative impact of excessive contact with L1 speakers, Robinson (1995) considers that interactions with members of one's first culture may be essential for continued learning. She notes that

It may be that to be an effective language learner, one needs 'down times' from learning and venting of culture shock with compatriots and to spend some time speaking English. While that would not meet the optimal conditions for language exposure, it might be a necessary part of the buman adjustment process (201-202).

Thus, the relationship of intra-cultural to inter-cultural interaction may have both positive and negative ramifications.

While cross-cultural issues certainly affect learners' study abroad experience, many more studies point to the influence of personal variables or individual learner differences to explain learners' rejection of social interaction in the L2. Polanyi (1995), for example, investigates the influence students' gender has on their social interaction in the L2. Following a finding reported by Brecht, Davidson, and Ginsberg (1995) that the oral and listening proficiency of young women did not cross the $1+$ to 2 (Intermediate High to Advanced) oral proficiency rating ${ }^{4}$ as frequently as that of young men on the same SA program, Polanyi conducted a qualitative analysis of the diaries produced by those students to identify differences in their social encounters. Polanyi found that women frequently 
reported unpleasant encounters with Russian men that tended to lead to feelings of self-doubt, social awkwardness, and worry. The men's reports, however, tended toward pleasant encounters with Russian women, noting that the potential for sexual or intimate relations did not cause the same feelings of discomfort and anxiety among the men as those the women had reported.

Exploring the diaries of the same SA groups as Polanyi, Brecht and Robinson (1993) report similar findings of qualitative differences between the experiences of men and women during SA. According to Brecht and Robinson, the American women often felt they were not included as equals in conversations with NSs as were the American men due to gender roles in the target culture. Women's exclusion, consequently, led to less conversation, especially concerning more "intellectual" topics. Schumann (1980) encountered similar cultural discriminations in her study of Farsi in Iran. She writes, "There [in the target culture] the opportunities abound for the language student. No one ever informed the female $^{5}$ language learner that in any given daily contact situation in Iran a good many of these opportunities are 'off bounds' " (55). Not only may the gender of the student affect experiences, but students' perceptions of gender differences in the target culture may also cause them to be discriminating in their choice of interlocutors. Pellegrino (1996a; 1996b) reports gender differences in students' preferred choice of interlocutor: if speaking Russian with another American, $79 \%$ of the respondents claimed they had no preference for the gender of the interlocutor, while $13 \%$ preferred speaking Russian with women and $8.5 \%$ preferred speaking Russian with men. If, however, students were speaking Russian with a native speaker, only one third claimed to have no preference, yet $86.5 \%$ of those reporting a preference were more inclined to speak with a Russian woman than a Russian man. Male participants expressed slightly less preference than female participants in the gender of their interlocutors, which suggests that the female participants may have a greater tendency to reject or avoid interactions with Russian males, essentially cutting interactive communication opportunities in half. Nonetheless, of the male participants, nearly half (47.6\%) still preferred speaking with Russian females. A preliminary investigation into the descriptive explanations for these preferences suggest reasons similar to those reported by Polanyi (1995), Brecht and Robinson (1993), and Schumann (1980), yet further research 
in this area may provide new insights.

More important than the identity of learners' interlocutors, however, appears to be the actual behavior of the NS interlocutors toward the learners themselves. As Campbell (1996) notes, interaction in an L2 involves a high degree of personal and social risk. Learners' attempts to communicate and establish relationships with NSs may be unsuccessful or rejected by the NSs, leaving learners embarrassed, discouraged, and unmotivated to pursue further interactions. Pellegrino (1997a, 1997b) examined the social and psychological factors underlying learners' rejection or acceptance of social interaction by conducting a grounded theory analysis $^{6}$ of the journals and interviews of six American students studying Russian abroad for four- and ten-month periods on academic programs sponsored by the American Council of Teachers of Russian. Based on learners' reports, Pellegrino found that in order to interact with NSs in the L2, learners needed to feel that their "social psychological security" was maintained or elevated, both by their social environment (in terms of interlocutors' and observers' behaviors and persona) and by their own attitudes and ability to predict the course of the interaction (e.g., through their sense of familiarity and commonality with the interlocutors, etc.). Pellegrino characterizes "social psychological security" according to four aspects: "a) learners need to feel that their status as a mature, intelligent adult is preserved, b) they need to feel a sense of physical and affective safety, c) they need to feel supported that their concerns, thoughts, questions, and efforts to speak are valid and worthy of others' attention and interest, and d) they need to feel they have a reasonable amount of control over their L2 use environment" (1997a, 71). When learners perceive threatening behaviors from interlocutors, such as insulting feedback, harsh correction, or unfavorable comparison to other speakers, they are more likely to avoid interaction unless they are able to maintain their social psychological security via learner-internal sources, such as positive attitudes and a reasonable sense of predictability for the outcomes of their efforts.

Pellegrino's concepts of validation by others and status within interactions seem to be frequently supported in studies noting the behavior of interlocutors. According to studies of students' perspectives, interlocutors' behavior appears to be one of the most widely noted deterrents to social interaction in introspective studies. Several studies acknowledge the 
importance of attentive interlocutors, as Polanyi (1995) notes, "even the most accomplished speaker becomes uncertain, mute, when language fails because no one is listening" (282). Similarly, Kline (1993) writes that "family responsiveness," in addition to "student initiatives," were "the key factors in reinforcing text-based interaction" (265). Schmidt and Frota (1986) note that in addition to being attentive, however, interlocutors need to show sensitivity in their language caretaking: "it is also clear that correction does have potentially adverse effects on the quality of interaction," potentially leaving the learner with "discomfort and ill feelings" and feeling "so angry I didn't talk at all for a couple of hours" (292). Such sensitivity and attentiveness includes respect for the students' language learning goals; as Schumann $(1977$; 1980) noted, learners may abandon language study completely if they object to the instructors' teaching methods or feel forced to accept the learning agenda of the pedagogical program over their own. Keating (1994) further stresses the importance of supportive interlocutor behavior since learners' "self doubt left them no less vulnerable than young children, and points to the need at all ages for sensitivity and encouragement on the part of the teacher" (61). Thus, interlocutor behaviors that affect learners' sense of status or validation may have a very strong impact on learners' use and ultimate acquisition of the L2, making the social environment in which learners use the L2 a vital factor in the language learning experience during study abroad.

Participants of study abroad programs today often have the opportunity to create an instant social environment in the form of the "homestay." As Wilkinson (1997) notes, the "homestay myth" holds that homestays contribute to students' L2 acquisition and development of cultural knowledge by immersing them in an authentic family environment. However, the same potential for negative social interactions exists in the specially-prepared homestay as in other spontaneous interactions. Wilkinson (1998) reports that one of her study's participants was offended by her host mother's behavior and “in this case, Amelia's perception that her host mother's reactions were condescending ultimately contributed to her decision to avoid returning home in the evenings until after she thought her family would be in bed" (27). Even in environments geared toward being supportive of learners, NS interlocutor behavior may prevent learners from fully using their L2 skills.

The behaviors of NS interlocutors may lead learners to feel inade- 
quate as members of a social group, which potentially may prevent them from making further efforts to participate. According to student perspective studies, however, feelings of inadequacy may also arise in light of difficulties learners have using their L2 to achieve communicative goals. For example, Moore (1977), in an examination of his own language learning journal written during his sojourn to Denmark, reflects on the social isolation he experienced due to his inability to participate in professional interactions at the same level as his NS colleagues. Warden et al. (1995), in their diary study of 18 anglophone high school students studying French in Quebec for three months, also reported a common fear of appearing stupid due to deficient language skills. Learners may experience such feelings of inadequacy as a result of comparing themselves to other learners. Schumann (1977) notes difficulties that arose in her language learning practices due to feelings of competition with her husband, who was also learning Farsi. Bailey (1983) corroborates Schumann's difficulties with competition, citing similar experiences in the diaries of classroom language learners. Pellegrino (1997a) also reported learners' tendency to compare their own L2 skills with those of others in order to establish a sense of status in the language learning group. Learners who viewed other learners as more capable than them tended to reduce their active participation in L2 interactions.

Popular opinion holds that SA is an effective means of second language acquisition in part because of the extensive opportunities it offers for authentic communication in the L2 and personal interaction with NSs. Certainly, students' perceptions of the classroom and expectations for interaction in the L2 attest to that widespread belief. However, introspective research also indicates that learners do not always take full advantage of opportunities that are handed to them. By closely examining the experiences of SA participants as described by them, it is possible to gain tremendous insight into the possible causes of such behavior and take initial steps toward aiding students in the SA social environment.

\section{Overall Effect of the Study Abroad Experience}

Extensive statistical research attests to the quantitative L2 proficiency benefits of the study abroad experience, yet they do not and can not 
adequately convey the personal growth and experience of study abroad. Even the more descriptive studies, such as many of those found in Freed (1995), that focus on the specific linguistic and sociolinguistic features that tend to characterize the speech of students who have been abroad, don't address students' own perceptions of the study abroad experience and the impact of that experience on their language learning. Learners' introspective narratives, however, provide glimpses into the qualitative communicative changes in their L2 knowledge and the personal growth that results from their time abroad. Regardless of quantifiable changes, learners often report great satisfaction with their language development during SA. Pellegrino (1996a; 1996b), for example, found in her survey of seventy-six American students studying Russian in Moscow and St. Petersburg that the majority of students $(87 \%)$ felt they put a lot of effort into learning Russian, and $79 \%$ reported that they were satisfied with the progress they made during the semester. Lennon (1989) also presented similar findings in his diary study of four German university students studying for six months at the University of Reading, England. He reports that the learners enthusiastically reported strong improvements in speaking and listening (although not reading and writing) during their time at the university due to the high amount of oral practice. Specifically, the students believed that the informal L2 environment was beneficial in several ways: it gave numerous opportunities for L2 comprehension practice, it stimulated the subjects to speak and interact with NSs, and it offered more colloquial, native-like, idiomatic L2 input than is available in the classroom. Meara (1994) also surveyed 586 British university students studying abroad for one year and found that those students who perceived themselves as having spent a great deal of time speaking the target language also perceived that they improved substantially on all language measures (speaking, listening, reading, and writing). Thus, as Pellegrino, Lennon, and Meara's findings suggest, students report a direct connection between their perceived language use and perceived language gain.

In addition to the linguistic benefits of SA, learners also report on the ways in which SA has changed them as individuals. These student perceptions have been gathered in studies that have taken a more holistic look at the SA experience to determine the net educational profit to be had by SA participants. Bicknese (1974), for example, conducted three separate surveys of American college students studying in Marburg, 
Germany, over the years of 1963 to 1966 . The surveys, which included both closed- and open-response items, were collected before the students departed for Germany, before they returned to the United States, and again ten months following the SA program. The results indicated that the SA participants experienced considerable changes in their opinions about themselves, the target language, the target culture, and their own culture and values. Bicknese reports that according to learners' responses:

The vast majority of the students gain an impressive proficiency in the target language; they penetrate the host culture far more deeply than they could in several years on their home campuses; they experience a liberal education in its broadest sense; they begin to construct for themselves a solid foundation of knowledge and personality, which will enable them to pass judgment more objectively throughout their lives; their linguistic skills and factual knowledge will qualify them for a great variety of professions in this world of shrinking geographic dimensions (345).

Bicknese notes that most learners came to show greater appreciation for their own culture, while learning to appreciate the unique qualities of the target culture. Participants also reported slight changes in their personal value system, showing more liberal attitudes toward premarital relations, smoking, alcohol, and rock music.

Like Bicknese, Laubscher (1994) also found that learners felt they had gained in terms of personal development during SA. His study's participants reported feeling more independent and self-reliant, more confident in their own abilities, and more tolerant and accepting of cultural and personal difference than they had been before studying in another country. Learners also reported greater objectivity in their views of their own country, being better able to recognize both positive and negative characteristics, and they gained a different understanding of their own personal identity. In their qualitative study of American high school students studying abroad, Warden et al. (1995) also found that their study's participants reported significant extralinguistic developments in terms of personal growth and knowledge of the target culture and society. Many reported an increase in their feeling of independence and success and had mixed reactions to leaving the host culture at the end of the program. 


\section{Lessons of Introspection: Insights into Study Abroad}

As the studies highlighted in this chapter have demonstrated, the texture and richness of students' perceptions of the study abroad experience provide tremendous insights into the benefits and costs of in-country language study in terms of linguistic development, cultural understanding, and personal growth. While the quantifiable language proficiency scales may be used as a metric for evaluating programs' efficiency, including arguments in favor of SA as a means of cost efficient language proficiency gain, such scales do not and can not provide a full picture of the study abroad context as it truly is experienced. Furthermore, such scales provide little, if any, diagnostic information concerning learners' success or failure during SA. Introspective studies have allowed researchers, pedagogues, administrators, and the students themselves to better understand the social, psychological, and academic phenomena that students undergo when they go abroad.

Perhaps the biggest lesson to be gained from a review of introspective literature, however, is the experience of using qualitative methods to examine SLA. As was stated early in this chapter, qualitative methods are often scorned as soft and unscientific. While this chapter speaks highly of the benefits of qualitative methods, the argument of their questionability must not be taken lightly. Researchers must be extremely cautious when turning to students' perspectives as representations of reality. The fact that personal impressions are subjective and biased make them both a blessing and a curse. Learners' perspectives are volatile, changing from moment to moment, depending on the events of the day. This is even evidenced by the stages of cultural development described here, where perceptions of cultural differences progress from quaint to grotesque as personal experiences accrue. Thus, great care must be taken when using introspective data. Were one to accept learners' condemnation of formal instruction at face value, for example, the benefits of the classroom may be lost if not even recognized by the inexperienced qualitative researcher. Moreover, narrative data, such as that from diaries and interviews, must be approached with extreme rigor of analysis; researchers' bias in some ways can be even greater than that of the students. Any researcher with preconceived notions of what students may say will surely find exactly that, 
fulfilling the researcher's agenda easily. Just as in statistical research, qualitative forms of data collection and analysis do have rigorous, prescribed protocols that must be fully understood before they are undertaken. Social research (such as in the fields of sociology, social psychology, and social work) have a well-established tradition of methodology training and a strong literature outlining such procedures. Moreover, Bailey (1983) offers researchers guidelines for conducting introspective studies in SLA research. Researchers who pay insufficient attention to the prescribed protocols of qualitative research methods call their findings into question and add fuel to arguments made against the use of perspective studies in the field of SLA.

It must be noted that questionnaire-based data should be approached with no less caution than narrative data. Unlike diaries and interviews, questionnaires offer a false sense of methodological security, appearing quantifiable and objective. Yet, they are subject to the same double bias (of both researcher and respondent) as any narrative diary or interview. Questionnaires are intended to look at learners' perspectives, yet the questions are necessarily and dangerously based on the researcher's perspectives of what participants may find important in their experience. This "filtering" of students' experience through that of the researcher limits the potential findings and prejudiciously colors the insights students offer. As with the diary studies, rigorous research protocols exist that should be considered before embarking on survey composition.

The findings of the studies presented in this chapter give fascinating insight into the perceptions of students about language and how it is learned, the effects of the classroom experience during study abroad, the negative effects of students' derogation of the classroom, the value of social interaction, the factors that prevent learners from interacting with NSs in the L2, and learners' views of their overall personal and academic development during study abroad. These findings may influence SA program coordinators and directors to anticipate students' difficulties while abroad and enhance the positive effects of the in-country experience. In addition, student perspective studies may also prove to be of great benefit to students who are preparing to go abroad or to those who are already studying in-country. Finally, the findings also lay important and solid groundwork for further investigation into areas that would not have been considered without listening to the voice of the students. 


\section{Notes}

1 The data used by Miller and Ginsberg were a subset of a larger body of data collected as part of a collaborative project between the American Council of Teachers of Russian (ACTR) and the National Foreign Language Center (NFLC), described elsewhere (Brecht, Davidson, \& Ginsberg, 1995; Brecht \& Robinson, 1993). These data were used in several of the studies reported on in the present article (Brecht and Robinson, 1995; Polanyi 1995; Robinson, 1995) and inspired data collection in other studies (Pellegrino 1996a, 1996b, 1997a, 1997b).

2 Emphasis added.

3 Emphasis in the original.

4 According to the ACTFL/FSI Oral Proficiency Scale.

5 Emphasis in the original

6 Grounded Theory Methodology, unlike other qualitative approaches that are used to describe a phenomenon, is used to generate theory through coding and conceptualization techniques. For more information, see Strauss and Corbin, 1990.

\section{Re f e re n c e s}

Aronson, E. 1995. The Social Animal. Seventh Edition. New York: W. H. Freeman and Co.

Bacon, S. M. 1995. Coming to grips with the culture: Another use of dialogue journals in teacher education. Foreign Language Annals 28 (2): 193-207.

Bailey, K. M. 1983. Competitiveness and anxiety in adult second language learning: Looking at and through the diary studies. Classroom oriented research in second language acquisition ed. by H. D. Seliger and M. H. Long, 67-103.

Bailey, K. M. and R. Ochsner. 1983. A methodological review of the diary studies: Windmill tilting or social science? Second Language Acquisition Studies ed. by K. M. Bailey, M. H. Long, and S. Peck. Rowley, MA: Newbury House Publishers, Inc. 
Bicknese, G. 1974. Study abroad. Part I: A Comparative Test of Attitudes and Opinions. Foreign Language Annals 7: 325-336.

Bicknese, G. 1974. Study abroad. Part II. As the students see it: The junior year abroad reassessed. Foreign Language Annals 7: 337-345.

Blender, E. 1998. Group Dynamics on Study Abroad Programs: Resident

Director Perceptions of their Students and Practical Strategies for Increasing L2 Interaction. MA Thesis. Bryn Mawr C.

Brecht, R. D. and J. L. Robinson. 1995. On the value of formal instruction in study abroad: Student reactions in context. Second Language Acquisition in a Study Abroad Context ed. B.F. Freed, 317-334. Amsterdam and Philadephia: John Benjamins.

Brecht, R. D. and J. L. Robinson. 1993. Qualitative Analysis of Second Language Acquisition in Study Abroad: The ACTR/NFLC Project. Washington, DC: The National Foreign Language Center Occasional Papers.

Brecht, R., D. Davidson, and R. Ginsburg. 1995. Predictors of Foreign Language Gain during Study Abroad. Second Language Acquisition in a Study Abroad Context ed. B.F. Freed. Amsterdam and Philadephia: John Benjamins.

Campbell, C. 1996. Socializing with the teachers and prior language learning experience: a diary study. Voices from the Language Classroom eds. K. M. Bailey and D. Nunan, 201-223. New York: Cambridge University Press.

Carlson, J. S. et al. 1990. Study Abroad: The Experience of American Undergrads. Contributions to the Study of Education, Number 37. New York: Greenwood Press.

Carroll, J. 1967. Foreign language proficiency levels attained by language majors near graduation from college. Foreign Language Annals 1: 131151.

Cholakian, R. 1992. Study Abroad: Paris. ADFL Bulletin 23 (2): 20-25.

Cohen, A. D. 1987. Using verbal reports in research on language learning. Introspection in Second Language Research eds. C. Færch and G. Kasper, 82-95. Philadelphia: Multilingual Matters, Ltd.

DeKeyser, R. M. 1991. Foreign language development during a semester abroad. Second Language Acquisition in a Study Abroad Context ed. B.F. Freed, 104-119. Amsterdam and Philadephia: John Benjamins.

Eisner, E. W. and A. Peshkin (eds.) 1990. Qualitative Inquiry in Education: 
The Continuing Debate. New York: Teachers College Press.

Erickson, F. Advantages and disadvantages of qualitative research design on foreign language research. Foreign Language Acquisition Research and the Classroom ed. B.F. Freed, 338-353. Lexington, MA: D. C. Heath and Co.

Færch, C. and G. Kasper. 1987. From product to process - Introspective methods in second language research. Introspection in Second Language Research eds. C. Færch and G. Kasper, 5-21. Philadelphia: Multilingual Matters, Ltd.

Freed, B. F. (ed.) 1995. Second Language Acquisition in a Study Abroad Context. Amsterdam and Philadelphia: John Benjamins.

Gillette, B. 1987. Two successful language learners: An introspective approach. Introspection in Second Language Research eds. C. Færch and G. Kasper, 268-279. Philadelphia: Multilingual Matters, Ltd.

Hanvey, R. 1979. "Cross-Cultural Awareness." Toward Internationalism: Readings in Cross-Cultural Communication. Rowley, MA: Newbury House.

Kaplan, M. A. 1989. French in the community: A survey of language use abroad. The French Review 63 (2): 290-301.

Keating, K. 1994. Findings from a qualitative study of adult learners of Spanish: Implications for approaches to second language programs for future teachers. Journal of Instructional Psychology 21 (1): 57-63.

Kline, R. R. 1993. The Social Practice of Literacy in a Program of Study Abroad. Dissertation. The Pennsylvania State University.

Larsen-Freeman, D. and M. H. Long. 1991. An Introduction to Second Language Acquisition Research. New York: Longman.

Laubscher, M. R. 1994. Encounters with difference: Student perceptions of the role of out-of-class experiences in education abroad. Westport, CT: Greenwood Press.

Lennon, P. 1989. Introspection and intentionality in advanced second-language acquisition. Language Learning 3 (3): 375-396.

Meara, P. 1994. The year abroad and its effects. Language Learning 10: 32-38.

Miller, L. and R. B. Ginsberg. 1995. Folklinguistic theories of language learning. Second Language Acquisition in a Study Abroad Context ed. B.F. Freed, 293-316. Amsterdam and Philadephia: John Benjamins.

Moore, T. 1977. An experimental language handicap (personal account). Bulletin of the British Psychological Society. 30: 107-110. 
Nunan, D. 1991. Methods in Second Language Classroom-Oriented Research: A Critical Review. Studies in Second Language Acquisition. 13: 249-274.

Pellegrino, V. 1996a. "Profile of a Study Abroad Group." unpublished manuscript.

Pellegrino, V. 1996b. Factors affecting risk-management behavior among students during study-abroad. AATSEEL Convention, Washington, DC. December 1996.

Pellegrino, V. 1997a. Social and psychological factors affecting spontaneous second language use during study abroad: A qualitative study. Dissertation. Bryn Mawr College.

Pellegrino, V. 1997b. Speaking Abroad: How interpersonal relations affect American students' use of Russian beyond the classroom. MLA Convention, Toronto. 29 December 1997.

Phillips, E. M. 1992. The effects of language anxiety on students' oral test performance and attitudes. The Modern Language Journal 76 (1): 14-26.

Polanyi, L. 1995. Language learning and living abroad: Stories from the field. Second Language Acquisition in a Study Abroad Context ed. B.F. Freed, 271-291. Amsterdam and Philadephia: John Benjamins.

Robinson, J. L. 1995. Second language learning in social context: An ethnographic account of an academic semester abroad in Russia. Dissertation. U. Maryland.

Schmidt, R. W. and S. N. Frota. 1986. Developing basic conversational ability in a second language: A case study of an adult learner of Portuguese. Talking to learn: Conversation in second language acquisition ed. R. R. Day, 237-326. Rowley, MA: Newbury House Publishers, Inc.

Schumann, F. M. 1980. Diary of a language learner: A further analysis. Research in second language acquisition: Selected papers of the Los Angeles Second Language Acquisition Research Forum ed. by R. C. Scarcella and S. D. Krashen, 51-65. Rowley, MA: Newbury House Publishers, Inc. Stansfield, C. W. 1975. "Study Abroad and the First-Year Student." System 3 (3): 198-203.

Strauss, A. and J. Corbin. 1990. Basics of Qualitative Research: Grounded Theory Procedures and Techniques. Newbury Park: Sage Publications.

Warden, M., S. Lapkin, M. Swain, and D. Hart. 1995. Adolescent language learners on a three-month exchange: Insights from their 
Frontiers: The Interdisciplinary Journal of Study Abroad

diaries. Foreign Language Annals 28 (4): 537-550.

Wilkinson, S. 1997. Separating fact from myth: A qualitative perspective on language learning during summer study abroad. MLA Convention, Toronto. 29 December 1997.

Wilkinson, S. 1998. Study abroad from the participants' perspective: A challenge to common beliefs. Foreign Language Annals 31 (1): 23-39. 